\title{
A Survey of Noninvasive Ventilation Practices in a Respiratory ICU of North India
}

\author{
Sunil Sharma MD DM, Ritesh Agarwal MD DM, Ashutosh N Aggarwal MD DM, \\ Dheeraj Gupta MD DM, and Surinder K Jindal MD DM
}

\begin{abstract}
BACKGROUND: There is paucity of data from India on the use of noninvasive ventilation (NIV) in acute respiratory failure (ARF). In this observational study, we report the indications and outcomes of patients requiring NIV in the respiratory ICU of a tertiary care hospital. METHODS: All patients with ARF requiring NIV were included in the study. NIV was delivered through critical care ventilators, using oronasal mask. The disease severity and new-onset organ dysfunction/failure were calculated using the Acute Physiology and Chronic Health Evaluation (APACHE II) and Sequential Organ Failure Assessment (SOFA) scores, respectively. A multivariate logistic regression model was used to analyze the factors predicting NIV failure. RESULTS: There were 92 subjects (48 men, 44 women, mean \pm SD age $48 \pm 17.5$ y) who received 101 NIV applications (42 and 59 applications for episodes of hypoxemic and hypercapnic ARF, respectively) during the study period. The most common causes of hypoxemic and hypercapnic respiratory failure were acute lung injury/ARDS (29\%) and COPD (29\%), respectively. There was significant improvement in heart rate and respiratory rate after 1, 2, and 4 hours, compared to the baseline, in both the groups. Of the NIV applications, 53.5\% required endotracheal intubation, with the number being significantly higher in hypoxemic (67\%), compared to hypercapnic (44\%), ARF $(P=.03)$. The $\mathrm{P}_{\mathrm{aO}_{2}} / \mathrm{F}_{\mathrm{IO}_{2}}$ measured after 1 hour of NIV application had significant impact on outcome in patients with hypoxemic but not hypercapnic ARF. A $\mathrm{P}_{\mathrm{aO}_{2}} / \mathrm{F}_{\mathrm{IO}_{2}}$ of $\leq 146 \mathrm{~mm} \mathrm{Hg}$ at one hour had a better specificity $(85.7 \%$ vs 71.4\%), versus a $\mathrm{P}_{\mathrm{aO}} / \mathrm{F}_{\mathrm{IO}}$ of $\leq 175 \mathrm{~mm} \mathrm{Hg}$ in predicting NIV failure in patients with hypoxemic ARF. On multivariate logistic regression analysis, baseline APACHE II score, $\triangle$ SOFA score, hypoxemic respiratory failure, and change in $\mathrm{P}_{\mathrm{aO}}{ }_{2} / \mathrm{F}_{\mathrm{IO}_{2}}$ at 1 hour from baseline were associated with NIV failure. CONCLUSIONS: NIV was found to be a useful modality in management of patients with hypercapnic versus hypoxemic respiratory failure. The severity of illness at admission, newonset organ dysfunction, hypoxemic $A R F$, and delay in improvement in $\mathrm{P}_{\mathrm{aO}} \mathrm{O}_{2} / \mathrm{F}_{\mathrm{IO}_{2}}$ at 1 hour from baseline are independent predictors of NIV failure. Key words: noninvasive ventilation; NIV; respiratory failure; ARDS; COPD. [Respir Care 2012;57(7):1145-1153. (C) 2012 Daedalus Enterprises]
\end{abstract}

\section{Introduction}

Noninvasive ventilation (NIV) refers to delivery of mechanical ventilation to the lungs, using techniques that do not require an endotracheal airway. The widespread use of NIV began with the discovery that CPAP could improve gas exchange and daytime somnolence of obstructive sleep

The authors are affiliated with the Department of Pulmonary Medicine, Postgraduate Institute of Medical Education and Research, Chandigarh, India.

The authors have disclosed no conflicts of interest. apnea. ${ }^{1}$ Subsequently, NIV has been successfully applied to chronic respiratory failure due to neuromuscular causes and severe kyphoscoliosis. ${ }^{2}$ NIV has also been evaluated in diverse causes of acute respiratory failure (ARF), and can potentially obviate the need for endotracheal intubation and reduce the occurrence of nosocomial infections,

\footnotetext{
Correspondence: Ritesh Agarwal MD DM, Department of Pulmonary Medicine, Postgraduate Institute of Medical Education and Research, Sector 12, Chandigarh 160012, India. E-mail: riteshpgi@gmail.com; agarwal.ritesh@pgimer.edu.in.
}

DOI: $10.4187 /$ respcare. 01541 
duration of ICU stay, and the overall cost of hospitalization. ${ }^{3}$

NIV is currently considered the standard of care in exacerbations of COPD, with its use associated with reduced tracheal intubation, duration of hospitalization, and mortality. ${ }^{4-8}$ On the other hand, the use of NIV in severe acute asthma is not widely accepted. ${ }^{9}$ The role of NIV in weaning and post-extubation respiratory failure also remains controversial. ${ }^{10,11}$ The application of NIV in hypoxemic ARF has also been an area of research over the last 2 decades. ${ }^{12}$ Two recent meta-analyses of randomized controlled trials found no robust evidence to support the role of NIV in hypoxemic ARF and acute lung injury (ALI)/ ARDS respectively. ${ }^{13,14}$ However, the use of NIV in specific settings of hypoxemic ARF (pneumonia in immunocompromised hosts and post lung resection surgery) has been shown to reduce endotracheal intubation rates and even mortality. ${ }^{15-17}$ In ARF due to cardiogenic pulmonary edema (CPE), the use of NIV has been shown to reduce mortality in meta-analyses, ${ }^{18,19}$ but a recent large trial failed to demonstrate any survival advantage. ${ }^{20}$

We have earlier described the factors predicting outcome in patients with ARF in COPD versus other causes. ${ }^{21}$ Subsequently, we described the outcomes of patients with hypoxemic ARF in our respiratory ICU (RICU). ${ }^{22}$ Recently, we described the role of NIV in severe acute asthma. ${ }^{23}$ However, these studies from our ICU may not be a true reflection of the actual ICU practice, and are limited by a selection bias in inclusion of a specific group of patients. Moreover, in most of the ICUs in teaching hospitals in India, only the most seriously ill patients are admitted, due to overcrowding in the emergency department. There are also differences in resources, and the case mix from developing countries is likely to be different from the developed world. Hence, the outcomes with NIV application may be different. There is also great importance in international comparison of NIV data. However, there is a paucity of data on the use of NIV in ARF from India. In fact, there are only 5 published studies that have investigated the use of NIV in patients with ARF from India. ${ }^{21-25}$ In this observational study we report the indications and outcomes of all patients admitted in our RICU requiring NIV at admission or during the ICU stay.

\section{Methods}

\section{Study Design and Patient Selection}

This was a prospective observational study conducted in the RICU of this institution. All patients admitted to RICU between January 1, 2009, and March 31, 2010, who received NIV for management of ARF were included in this study. The RICU is an 8-bed ICU with a total of 8 pulmonary fellows ( 5 posted in a day), 5 consultants, and a

\section{QUICK LOOK}

\section{Current knowledge}

Noninvasive ventilation (NIV) is a standard of care for exacerbations of COPD and acute cardiogenic pulmonary edema. Despite this fact, NIV remains underutilized in the United States. The utilization of NIV in India is not well known.

\section{What this paper contributes to our knowledge}

NIV was found to be a useful modality in hypercapnic respiratory failure, while its use in hypoxemic respiratory failure was less successful. Disease severity at admission, occurrence of new organ dysfunction, hypoxemic respiratory failure, and delay in improvement in $\mathrm{P}_{\mathrm{aO}_{2}} / \mathrm{F}_{\mathrm{IO}_{2}}$ at one hour from baseline were independent predictors of poor outcome with NIV. These findings in a tertiary care hospital in India are similar to those in North America and Europe.

nurse to patient ratio of 2:1. The unit has been using NIV since the year 2000, and has considerable expertise with the application of NIV. The entire faculty and all fellows are well trained during their residency in intubation and invasive ventilation. The study was approved by the institute's ethics committee, and written informed consent was obtained from all patients or the next of kin.

This study observed patients in our ICU receiving NIV based on the following established protocol. NIV is administered in patients with ARF, defined by the presence of both of the following criteria:

- Clinical symptoms and signs of acute respiratory distress, such as dyspnea, respiratory rate $>30$ breaths/ min, use of accessory muscles of respiration, or the presence of paradoxical breathing, and

- Arterial blood gas analysis showing $\mathrm{pH} \leq 7.35$ with $\mathrm{P}_{\mathrm{aO}_{2}} / \mathrm{F}_{\mathrm{IO}_{2}}<300 \mathrm{~mm} \mathrm{Hg}$ (or $\mathrm{P}_{\mathrm{aO}_{2}}<60 \mathrm{~mm} \mathrm{Hg}$ ) while the patient was breathing oxygen through an air-entrainment mask.

Patients are excluded from NIV application if they have any one of the following criteria: cardiac or respiratory arrest, hypotension (systolic blood pressure $<90 \mathrm{~mm} \mathrm{Hg}$ ), severe encephalopathy (Glasgow coma scale score $<8$ ), upper gastrointestinal bleeding, hemodynamic instability, unstable cardiac arrhythmia, upper-airway obstruction, inability to protect the airway and clear respiratory secretions, or abnormalities that preclude proper fit of the interface (agitated or uncooperative patient, facial trauma or burns, facial surgery, or facial anatomical abnormality). 


\section{A Survey of Noninvasive Ventilation Practices in a Respiratory ICU of North India}

\section{Definitions}

Pneumonia was defined by presence of fever, leukocytosis, purulent secretions, new or progressive chest radiographic infiltrates or pathological bacteria in the tracheobronchial secretions. ALI/ARDS was defined by acute onset of symptoms, bilateral pulmonary infiltrates, $\mathrm{P}_{\mathrm{aO}_{2}} / \mathrm{F}_{\mathrm{IO}_{2}}$ $<300 \mathrm{~mm} \mathrm{Hg}$ on room air, and no clinical evidence of cardiac cause for the pulmonary infiltrates. Exacerbation of $C O P D$ was defined according to the Global Initiative for Chronic Obstructive Lung Disease (GOLD) guidelines, characterized by a change in baseline dyspnea, cough, and/or sputum beyond day-to-day variability sufficient to warrant a change in management along with respiratory acidosis, and $\mathrm{pH}<7.35 .{ }^{26}$ Patients received NIV for postextubation respiratory failure in the first 48 hours after extubation if they developed a respiratory rate $>35$ breaths/ min (or an increase in respiratory rate of $>50 \%$ from baseline) with use of accessory muscles of respiration or abdominal paradox.

Preemptive NIV for post-extubation respiratory failure was administered to those deemed at high risk of developing respiratory failure following extubation. ${ }^{10}$ High-risk patients included patients with generally 2 or more of the following factors: age $>65$ years, more than one consecutive failure of weaning trial, chronic heart failure, $\mathrm{P}_{\mathrm{aCO}_{2}}$ $>50 \mathrm{~mm} \mathrm{Hg}$ after extubation, more than one medical/ surgical comorbid illness, poor cough reflex, upper-airway stridor at extubation that does not require immediate reintubation, and Acute Physiology and Chronic Health Evaluation (APACHE II) score $>12$ on the day of extubation. Severe acute asthma was defined by the presence of most of the following criteria: history of asthma of at least one year; patient judged by the attending physician as having an acute attack of asthma (acute respiratory distress with wheeze, inability to complete one sentence in one breath); respiratory rate $>30$ breaths/min; heart rate $>100$ beats/ min; and $\mathrm{S}_{\mathrm{pO}_{2}}<92 \%$ (or $\mathrm{P}_{\mathrm{aO}_{2}}<60 \mathrm{~mm} \mathrm{Hg}$ ). ${ }^{23}$ Cardiogenic pulmonary edema was defined as acute respiratory distress with respiratory rate $>30$ breaths/min and orthopnea with chest radiograph findings consistent with pulmonary edema. ${ }^{20}$

\section{NIV Protocol}

NIV was delivered through the following critical care ventilators: Galileo Gold (Hamilton Medical, Bonaduz, Switzerland), Evita 2 Dura (Dräger Medical, Lübeck, Germany), and Servo-i (Maquet Critical Care, Solna, Sweden). The interface used was silicon oronasal mask with inflatable cushion (VBM Medizintechnik, Germany). NIV was started at an inspiratory positive airway pressure (IPAP)/expiratory positive airway pressure (EPAP) of $6-8 / 3-4 \mathrm{~cm}$ of $\mathrm{H}_{2} \mathrm{O}$ and was gradually increased by $2 / 1 \mathrm{~cm}$ of $\mathrm{H}_{2} \mathrm{O}$ till clinical response, in the form of relief of dyspnea, respiratory rate $\leq 30$ breaths $/$ min, tidal volume $\geq 6$ $8 \mathrm{~mL} / \mathrm{kg}$, and $\mathrm{S}_{\mathrm{pO}_{2}} \geq 92 \%$ was achieved, or a maximum IPAP/EPAP of $20 / 10 \mathrm{~cm}$ of $\mathrm{H}_{2} \mathrm{O}$ was reached. During the initial 24 hours, disconnection of NIV was allowed only for intake of food and to clear oral secretions. Thereafter, depending upon the clinical response, the period off NIV was gradually increased, till patient could maintain $\mathrm{S}_{\mathrm{pO}_{2}}$ $\geq 92 \%$ on room air or respiratory rate of $\leq 30$ breaths/ $\min$.

\section{End Points}

The demographic details of the patients, including age, sex, type of respiratory failure, indication for NIV, and the presence of comorbid illnesses were recorded. The disease severity was calculated using the APACHE II score and Sequential Organ Failure Assessment (SOFA) score. Newonset organ dysfunction/failure was computed using the change in the SOFA score ( $\triangle$ SOFA), by subtracting the admission SOFA score from the maximum SOFA score during RICU stay. ${ }^{27} \mathrm{We}$ collected the data for heart rate, respiratory rate, systolic blood pressure, diastolic blood pressure, arterial blood gases $\left(\mathrm{pH}, \mathrm{P}_{\mathrm{aO}}, \mathrm{P}_{\mathrm{aCO}_{2}}\right)$ at baseline, 1 hour, 2 hours, 4 hours, and every 24 hours till patient discharge. The primary outcomes were failure of NIV (defined as number of patients requiring endotracheal intubation), time to endotracheal intubation after starting NIV, and RICU and hospital stay. The secondary outcomes were improvement in clinical and blood gas values assessed at 1,2, and 4 hours, hospital mortality, duration of NIV, maximum IPAP, and maximum EPAP, and time to maximum IPAP and maximum EPAP. Complications of NIV, such as claustrophobia, intolerance, abdominal distention, pressure sores, and nasal bridge trauma, were also noted. Patient discomfort was assessed by visual analog scale, with a scale of $0-100$ marked by the ICU physician. It was marked as zero if there was no discomfort and 100 for maximum discomfort.

The decision to terminate NIV and move to invasive ventilation was based on the following criteria: failure in improvement of clinical parameters and gas exchange at 1 hour; development of alteration in sensorium; hemodynamic instability; and inability to tolerate oronasal mask. However, the final decision was left to the intensivist's clinical judgment.

\section{Statistical Analysis}

Results are presented in a descriptive fashion as number and percentage or mean \pm SD unless otherwise stated. The difference between means of continuous and categorical variables was analyzed using the Mann-Whitney $\mathrm{U}$ and chi-square test, respectively. Improvements in clinical (re- 


\section{A Survey of Noninvasive Ventilation Practices in a Respiratory ICU of North India}

spiratory and heart rate) and arterial blood gas parameters $\left(\mathrm{pH}, \mathrm{P}_{\mathrm{aO}_{2}}\right)$ were analyzed using multifactorial repeated measures analysis of variance, with Bonferroni adjustment for multiple comparisons; the within-groups factor was time (baseline, 1, 2, and 4 hours), and the between-groups factor was the type of ARF (hypoxemic vs hypercapnic). A survival curve was constructed to study the time to intubation in patients failing NIV, using Kaplan-Meier analysis. Multivariate logistic regression analysis was performed to derive adjusted odds ratios and $95 \%$ confidence intervals to analyze the factors predicting NIV failure. Statistical significance was assumed at a $P$ value of $<.05$.

\section{Results}

Of the 313 admissions in the RICU during the study period, 185 were mechanically ventilated, 77 required only oxygen, and 51 received NIV on admission. Overall, 92 subjects received 101 NIV applications during the study period, with 42 and 59 for episodes of hypoxemic and hypercapnic ARF, respectively (Table 1). The most common causes of hypoxemic and hypercapnic respiratory failure were ALI/ARDS and COPD, respectively (see Table 1). There were $48(52.2 \%)$ men and $44(47.8 \%)$ women, with a mean \pm SD age of $48 \pm 17.5$ years. The baseline characteristics of the subjects with hypoxemic and hypercapnic respiratory failure are shown in Table 2. The severity of illness assessed by APACHE II and SOFA scores were similar in the 2 groups. However, subjects with hypercapnic respiratory failure were older and there was a significant difference in baseline heart rate, respiratory rate, $\mathrm{pH}$, and $\mathrm{P}_{\mathrm{aO}_{2}} / \mathrm{F}_{\mathrm{IO}_{2}}$ between the 2 groups (see Table 2). All subjects received appropriate medical management in addition to the NIV.

There was significant improvement in heart rate and respiratory rate after 1,2 , and 4 hours, compared to the baseline, in both the groups, and both the values significantly decreased in patients with hypoxemic, compared to hypercapnic, respiratory failure (Table 3 ). There was no significant change in $\mathrm{pH}$ values in the first 4 hours after NIV application. The $\mathrm{P}_{\mathrm{aO}}$ values were significantly different at 2 and 4 hours, compared to baseline, within the groups, but there was no significant difference between the groups (see Table 3 ). The mean \pm SD IPAP and EPAP used were $12.6 \pm 4.3$ and $5.2 \pm 1.2 \mathrm{~cm} \mathrm{H}_{2} \mathrm{O}$, respectively, and were not significantly different in the 2 groups. NIV was well tolerated, and patient discomfort on NIV, as assessed by visual analog scale, ranged from 0 to 100 , with the median (and IQR) score being 15 (2.5-20). The most common complication observed was occurrence of pressure sore due to NIV mask. Other complications were claustrophobia, abdominal distention, and asynchrony.

Of the 101 NIV applications, 54 (53.5\%) instances required endotracheal intubation, with the number being
Table 1. Etiology of Acute Respiratory Failure Requiring 101 Applications of NIV in the Respiratory ICU

\begin{tabular}{lc}
\hline \hline \multicolumn{1}{c}{ Etiology } & no. (\%) \\
\hline Type 1 Respiratory Failure & \\
ALI/ARDS & $12(28.6)$ \\
Pneumonia & $11(26.2)$ \\
Interstitial lung diseases & $9(21.4)$ \\
Bronchial asthma & $4(9.5)$ \\
Others* & $6(14.3)$ \\
Type 2 Respiratory Failure & $17(28.8)$ \\
COPD & $12(20.3)$ \\
Preemptive therapy of post-extubation & \\
$\quad$ respiratory failure & $9(15.3)$ \\
Bronchial asthma & $8(13.6)$ \\
Post-extubation respiratory failure & $7(11.8)$ \\
Allergic bronchopulmonary aspergillosis & $3(5.1)$ \\
Myasthenic crisis & $3(5.1)$ \\
Others $\dagger$ & \\
\hline * Diffuse alveolar hemorrhage, pulmonary embolism, pulmonary edema. & \\
$\dagger$ Obstructive sleep apnea hypopnea syndrome, pulmonary edema & \\
NIV $=$ noninvasive ventilation & \\
ALI $=$ acute lung injury & \\
\hline
\end{tabular}

significantly higher in hypoxemic, compared to hypercapnic, ARF (Table 4). Figure 1 depicts the time to endotracheal intubation. The mean time to intubation was $15.4 \mathrm{~h}(95 \% \mathrm{CI} 10.5-20.3 \mathrm{~h})$. The $\mathrm{P}_{\mathrm{aO}_{2}} / \mathrm{F}_{\mathrm{IO}_{2}}$ at 1 hour had significant impact on outcome in subjects with hypoxemic respiratory failure. $\mathrm{A}_{\mathrm{aO}_{2}} / \mathrm{F}_{\mathrm{IO}_{2}} \leq 146 \mathrm{~mm} \mathrm{Hg}$ (or $\leq 175 \mathrm{~mm} \mathrm{Hg}$ ) was associated with higher incidence of failure, while those with $\mathrm{P}_{\mathrm{aO}_{2}} / \mathrm{F}_{\mathrm{IO}_{2}}>146 \mathrm{~mm} \mathrm{Hg}$ had successful outcomes in $60 \%$ of the instances (Table 5). The sensitivity and specificity of $\mathrm{P}_{\mathrm{aO}_{2}} / \mathrm{F}_{\mathrm{IO}_{2}} \leq 146 \mathrm{~mm} \mathrm{Hg}$ and $\leq 175 \mathrm{~mm} \mathrm{Hg}$ in predicting NIV failure were $66.7 \%$ and $85.7 \%$, and $75 \%$ and $71.4 \%$, respectively. $\mathrm{P}_{\mathrm{aO}_{2}} / \mathrm{F}_{\mathrm{IO}_{2}}$ had no bearing on the outcome of subjects with hypercapnic ARF. The times to achieve maximum pressures with NIV, duration of NIV, time to intubation, ICU and hospital stay, and hospital mortality were similar in the 2 groups (Table 6). Out of 92 subjects, 62 (68.4\%) were discharged, while 30 subjects died during the hospital stay. On multivariate logistic regression analysis, baseline APACHE II score, $\triangle$ SOFA score, hypoxemic respiratory failure, and change in $\mathrm{P}_{\mathrm{aO}} / \mathrm{F}_{\mathrm{IO}_{2}}$ at 1 hour from baseline were associated with NIV failure (Table 7).

\section{Discussion}

The results of this study suggests that NIV is not a commonly used modality in our RICU, with only $17 \%$ of patients receiving NIV at admission, and overall $30 \%$ receiving NIV at any point during their ICU stay. NIV was used most often in subjects with hypercapnic respiratory 


\section{A Survey of Noninvasive Ventilation Practices in a Respiratory ICU of North India}

Table 2. Baseline Characteristics of 92 Subjects Who Received NIV in the Respiratory ICU

\begin{tabular}{|c|c|c|c|c|}
\hline & $\begin{array}{l}\text { Hypoxemic Respiratory Failure } \\
\qquad(n=38)\end{array}$ & $\begin{array}{l}\text { Hypercapnic Respiratory Failure } \\
\qquad(n=54)\end{array}$ & $\begin{array}{l}\text { Total Group } \\
(n=92)\end{array}$ & $P$ \\
\hline Age, y & $42.1 \pm 18.4$ & $52.7 \pm 15.6$ & $48 \pm 17.6$ & .002 \\
\hline Female, no. (\%) & $17(44.7)$ & $27(50)$ & $44(47.8)$ & .16 \\
\hline APACHE II score & $14.1 \pm 6.59$ & $12.9 \pm 5.17$ & $13.4 \pm 5.79$ & .37 \\
\hline SOFA score at admission & $4.6 \pm 2.9$ & $3.7 \pm 2.2$ & $4.1 \pm 2.5$ & .08 \\
\hline $\mathrm{f}$, breaths/min & $47.6 \pm 12.8$ & $37.8 \pm 11.4$ & $39.5 \pm 13.8$ & $<.001$ \\
\hline Heart rate, beats/min & $125.1 \pm 23.7$ & $109.1 \pm 18.3$ & $116.0 \pm 22.0$ & $<.001$ \\
\hline $\mathrm{pH}$ & $7.42 \pm 0.06$ & $7.32 \pm 0.08$ & $7.36 \pm 0.09$ & $<.001$ \\
\hline $\mathrm{P}_{\mathrm{aO}_{2}} / \mathrm{F}_{\mathrm{IO}_{2}}, \mathrm{~mm} \mathrm{Hg}$ & $134.5 \pm 51.4$ & $190.8 \pm 85.4$ & $125.1 \pm 77.9$ & $<.001$ \\
\hline $\mathrm{P}_{\mathrm{aCO}_{2}}, \mathrm{~mm} \mathrm{Hg}$ & $36.6 \pm 10.9$ & $67.7 \pm 18.4$ & $54.8 \pm 22$ & $<.001$ \\
\hline \multicolumn{5}{|c|}{$\begin{array}{l}\text { All values are mean } \pm \text { SD unless otherwise stated. } \\
\text { NIV = noninvasive ventilation } \\
\text { APACHE = Acute Physiology and Chronic Health Evaluation } \\
\text { SOFA = Sequential Organ Failure Assessment } \\
\mathrm{f}=\text { respiratory frequency }\end{array}$} \\
\hline
\end{tabular}

Table 3. Serial Clinical and Arterial Blood Gas Parameters During the ICU Course of the 2 Groups Receiving 101 NIV Applications

\begin{tabular}{|c|c|c|c|c|c|c|c|c|}
\hline & \multicolumn{4}{|c|}{ Hypoxemic Respiratory Failure $(n=42)$} & \multicolumn{4}{|c|}{ Hypercapnic Respiratory Failure $(n=59)$} \\
\hline & $0 \mathrm{~h}$ & $1 \mathrm{~h}$ & $2 \mathrm{~h}$ & $4 \mathrm{~h}$ & $0 \mathrm{~h}$ & $1 \mathrm{~h}$ & $2 \mathrm{~h}$ & $4 \mathrm{~h}$ \\
\hline Heart rate, beats/min & $123.9 \pm 23.2$ & $116.0 \pm 20.9^{*}$ & $113.1 \pm 21.5 \dagger$ & $110.4 \pm 19.6$ & $107.7 \pm 17.6$ & $106.1 \pm 17.7 * \S$ & $103.2 \pm 18 \dagger \S$ & $104.5 \pm 19.9 \ddagger \S$ \\
\hline $\mathrm{f}$, beats/min & $44.6 \pm 9.8$ & $35.7 \pm 10.0 *$ & $34.3 \pm 9.8 \dagger$ & $33.1 \pm 11.2 \ddagger$ & $33.8 \pm 12.0$ & $29.7 \pm 6.9 * \S$ & $28.3 \pm 7.1 \dagger \S$ & $28.8 \pm 9.0 \ddagger \S$ \\
\hline $\mathrm{pH}$ & $7.43 \pm 0.06$ & $7.42 \pm 0.04$ & $7.42 \pm 0.04$ & $7.43 \pm 0.04$ & $7.32 \pm 0.08$ & $7.32 \pm 0.07$ & $7.32 \pm 0.07$ & $7.33 \pm 0.08$ \\
\hline $\mathrm{P}_{\mathrm{aCO}_{2}}, \mathrm{~mm} \mathrm{Hg}$ & $35.9 \pm 7.3$ & $38.4 \pm 6.4$ & $38.2 \pm 5.9$ & $38.4 \pm 6.2$ & $66.8 \pm 19.5 \S$ & $69.1 \pm 23.8 \S$ & $68.2 \pm 19.4 \S$ & $68.9 \pm 22.0 \S$ \\
\hline $\mathrm{P}_{\mathrm{aO}_{2}}, \mathrm{~mm} \mathrm{Hg}$ & $58.7 \pm 13.7$ & $73.7 \pm 18.5$ & $78.7 \pm 18.5 \dagger$ & $81.8 \pm 26.9 \ddagger$ & $69.3 \pm 38.6$ & $73.7 \pm 30.5$ & $71.1 \pm 16.1 \dagger$ & $70.7 \pm 14.7 \ddagger$ \\
\hline \multicolumn{9}{|c|}{ 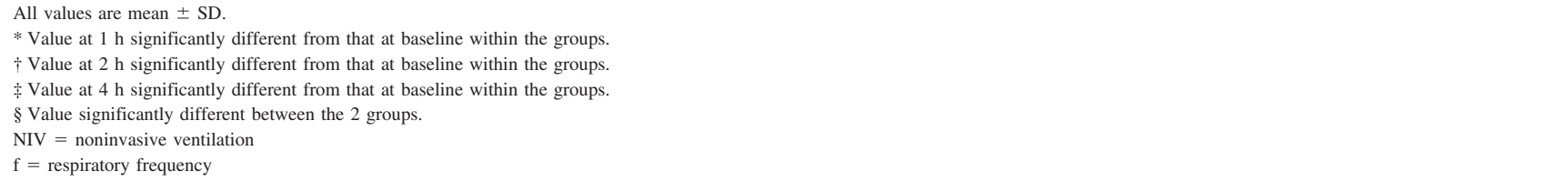 } \\
\hline
\end{tabular}

failure, with COPD constituting $28.8 \%$ of the cases, followed by other causes. The most definite indication for NIV is exacerbation of COPD, ${ }^{7}$ and COPD is generally the most common indication for NIV in many studies in patients with ARF. ${ }^{28-30}$ The most common indication in the group of patients with hypoxemic ARF was ALI/ARDS and pneumonia, similar to reported experience in the literature. ${ }^{15,31,32}$ Several studies have shown benefit in CPE; 20,33 however, the numbers of subjects with CPE were few in our study, as most of the patients are admitted and managed in a separate cardiac ICU in our institute.

The success rate of NIV in this study is comparable to rates described elsewhere, both from India ${ }^{24,25}$ and other centers. ${ }^{34-36}$ NIV has been shown to be beneficial in patients with ARF of diverse etiologies. ${ }^{25,28,37-39}$ In a study, Wysocki et al, after excluding patients with COPD and hypercapnic respiratory failure, found that NIV benefitted patients with hypercapnic respiratory failure of different etiologies; however, no benefit was observed in patients of ARF without hypercapnia. ${ }^{40}$ In this study the experience was similar, with the success rate being significantly higher in hypercapnic respiratory failure, and almost two thirds of subjects with hypoxemic respiratory failure failing NIV. The failure rates of NIV in exacerbations of COPD have ranged from $5 \%$ to $40 \% .^{4,41-43}$ The failure rates are toward the higher side in our study, possibly due to delay in admission to the RICU because of limited ICU beds and overcrowding in the emergency department.

The use of NIV has been shown to increase the tidal volume and decrease the inspiratory muscle effort, with consequent improvement in dyspnea and oxygenation status in patients with ALI. ${ }^{44}$ Despite these physiological benefits, evidence does not support its routine use in hypoxemic ARF. ${ }^{13,14,22,45}$ In a recent meta-analysis of 13 observational studies (540 patients) investigating the use of NIV in ALI/ARDS, the intubation rates varied from 
Table 4. Outcome of NIV in Terms of Requirement for Endotracheal Intubation Among the Various Groups of Acute Respiratory Failure

\begin{tabular}{|c|c|c|}
\hline Etiology & $\begin{array}{l}\text { Success, } \\
\text { no. }(\%)\end{array}$ & $\begin{array}{l}\text { Failure, } \\
\text { no. }(\%)\end{array}$ \\
\hline \multicolumn{3}{|l|}{ Type 1 Respiratory Failure } \\
\hline ALI/ARDS & $3(25)$ & $9(75)$ \\
\hline Pneumonia & $4(36.4)$ & $7(63.6)$ \\
\hline Interstitial lung diseases & $1(11.1)$ & $8(88.9)$ \\
\hline Bronchial asthma & $4(100)$ & \\
\hline Others* & $2(33.3)$ & $4(66.7)$ \\
\hline \multicolumn{3}{|l|}{ Type 2 Respiratory Failure } \\
\hline COPD & $10(58.8)$ & $7(41.2)$ \\
\hline $\begin{array}{l}\text { Preemptive therapy of post-extubation } \\
\text { respiratory failure }\end{array}$ & $12(100)$ & \\
\hline Bronchial asthma & $3(33.3)$ & $6(66.7)$ \\
\hline Post-extubation respiratory failure & & $8(100)$ \\
\hline Allergic bronchopulmonary aspergillosis & $4(57.1)$ & $3(42.9)$ \\
\hline Myasthenic crisis & $2(66.7)$ & $1(33.3)$ \\
\hline Others $\dagger$ & $3(100)$ & \\
\hline \multicolumn{3}{|c|}{$\begin{array}{l}\text { * Diffuse alveolar hemorrhage, pulmonary embolism, pulmonary edema. } \\
\dagger \text { Obstructive sleep apnea hypopnea syndrome, pulmonary edema } \\
\text { NIV = noninvasive ventilation } \\
\text { ALI = acute lung injury }\end{array}$} \\
\hline
\end{tabular}

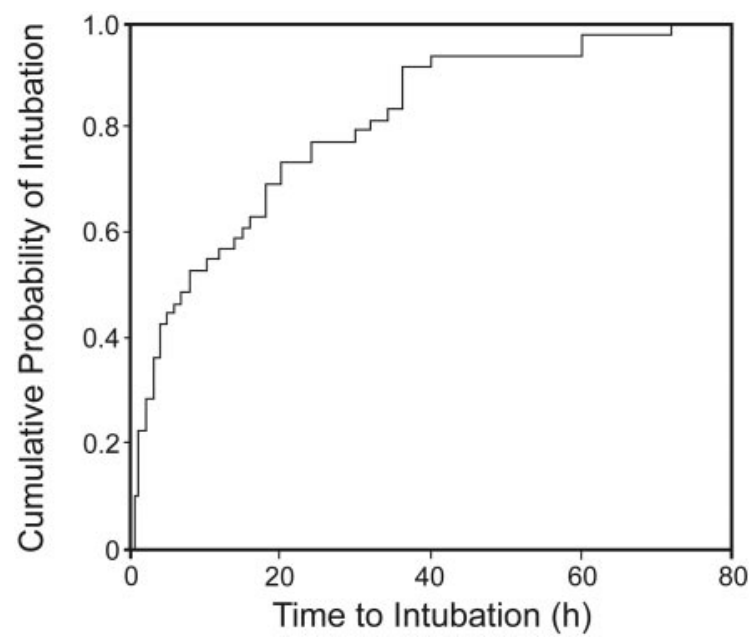

Fig. 1. Kaplan-Meier curve of the probability of endotracheal intubation over time in the 54 subjects failing noninvasive ventilation. Most intubations occurred in the first 24 hours.

$30-86 \% .^{45}$ This fact was also reflected in this study, with an almost $70 \%$ failure rate of NIV in pneumonia and ALI/ ARDS. For similar degrees of hypoxemia, the outcome of NIV depends on the etiology of the hypoxemic ARF. ${ }^{46}$ In a study that recruited patients with pneumonia and CPE with similar degrees of hypoxemia, the outcomes in pneumonia were worse, compared to CPE, despite an initial analogous improvement in oxygenation of the 2 groups. ${ }^{47}$ A French audit also confirmed benefit of NIV only in
CPE and COPD exacerbations, and not in de novo etiologies of ARF. ${ }^{48}$ Although NIV has been demonstrated to be as effective as conventional ventilation in correcting gas exchange in hypoxemic ARF, ${ }^{32}$ the presence of organ dysfunction and severity of illness are more important determinants of outcome with NIV.49-51

Currently there is no role for NIV in patients with postextubation respiratory failure, except as a preemptive therapy in high-risk patients (for reintubation) following extubation. ${ }^{10}$ All subjects with post-extubation respiratory failure in our study required intubation following NIV, whereas NIV was successful in high-risk subjects when given preemptively to prevent post-extubation respiratory failure. Significant improvement in lung function, reduction in the dose of inhaled bronchodilator, and shorter ICU stay in subjects with severe acute asthma were observed in 2 randomized controlled trials, and a trial of NIV is justified in patients who fail standard medical therapy. ${ }^{23,52}$ In the present study all asthmatics with hypoxemic respiratory failure had successful outcomes with NIV, while hypercapnic ARF in asthma was associated with NIV failure in two thirds. NIV has been used in acute deterioration of chronic respiratory insufficiency due to various neuromuscular diseases. ${ }^{53}$ Studies have shown good success rates with NIV in myasthenic crisis, ${ }^{54-56}$ with presence of hypercapnia associated with NIV failure. ${ }^{54,56}$ In the present study NIV was given to 3 subjects with myasthenic crisis, and was successful in 2 subjects.

In many patients, after application of NIV there is inability to obtain adequate ventilation, and eventually endotracheal intubation is required for the management of ARF. The intubation rates range from $15-40 \%$ and $35-$ $50 \%$ in COPD and non-COPD related respiratory failure, respectively. $5,6,35,36,46,51$ Some patients will initially benefit from NIV (for hours to a few days) but will then deteriorate and require intubation. ${ }^{57}$ The failure rates of NIV range from 5-50\%, depending on the etiology and severity of the ARF. ${ }^{46}$ Delays in endotracheal intubation have been shown to be associated with decreased survival in specific patient populations (pneumocystis pneumonia in the nonHIV population or in the emergency room) being managed with NIV. ${ }^{46,58}$ In a study, Wood et al reported $43.8 \%$ failure and increase in hospital mortality in the NIV group, probably related to delay in intubation. ${ }^{59}$ Thus, it is important to ascertain the factors associated with NIV failure, so that the high-risk subset of patients likely to fail an NIV trial can be predefined. Apart from the etiology of ARF, changes in arterial blood gases have been considered the best predictors, although respiratory rate has also been found to be a good predictor of response to NIV. ${ }^{60,61}$

We found that $\mathrm{P}_{\mathrm{aO}_{2}} / \mathrm{F}_{\mathrm{IO}_{2}}$ at 1 hour predicted outcome in subjects with hypoxemic $\mathrm{ARF}$, and a $\mathrm{P}_{\mathrm{aO}_{2}} / \mathrm{F}_{\mathrm{IO}_{2}}$ of $\leq 146 \mathrm{~mm} \mathrm{Hg}$ or $\leq 175 \mathrm{~mm} \mathrm{Hg}$ was associated with higher chances of NIV failure. Antonelli et al showed that 


\section{A Survey of Noninvasive Ventilation Practices in a Respiratory ICU of North India}

Table 5. Impact of $\mathrm{P}_{\mathrm{aO}} / \mathrm{F}_{\mathrm{IO}_{2}}$ Scores at 1 Hour and Outcome in Subjects Receiving NIV*

\begin{tabular}{|c|c|c|c|c|c|c|}
\hline & \multicolumn{3}{|c|}{ Hypoxemic Respiratory Failure } & \multicolumn{3}{|c|}{ Hypercapnic Respiratory Failure } \\
\hline & $\begin{array}{l}\text { Success } \\
(n=14)\end{array}$ & $\begin{array}{c}\text { Failure } \\
(n=24)\end{array}$ & $P$ & $\begin{array}{l}\text { Success } \\
(n=33)\end{array}$ & $\begin{array}{c}\text { Failure } \\
(n=23)\end{array}$ & $P$ \\
\hline \multicolumn{7}{|c|}{$\mathrm{P}_{\mathrm{aO}_{2}} / \mathrm{F}_{\mathrm{IO}_{2}}, \mathrm{~mm} \mathrm{Hg}$} \\
\hline$\leq 146$ & $2(14.3)$ & $16(66.7)$ & .003 & $7(21.2)$ & $3(13)$ & .50 \\
\hline$>146$ & $12(85.7)$ & $8(33.3)$ & & $26(78.8)$ & $20(87)$ & \\
\hline$\leq 175$ & $4(28.6)$ & $18(75)$ & .008 & $13(39.4)$ & $9(39.1)$ & .99 \\
\hline$>175$ & $10(71.4)$ & $6(25)$ & & $20(60.6)$ & $14(60.9)$ & \\
\hline
\end{tabular}

Values are no. (\%).

* Data of 94 applications as subjects were intubated within an hour during 7 instances of noninvasive ventilation (NIV) administration.

Table 6. Outcome Parameters During the ICU Course of the 2 Groups Receiving 101 NIV Applications

\begin{tabular}{|c|c|c|c|c|}
\hline & $\begin{array}{l}\text { Hypoxemic } \\
\text { Respiratory } \\
\text { Failure } \\
(n=42)\end{array}$ & $\begin{array}{l}\text { Hypercapnic } \\
\text { Respiratory } \\
\text { Failure } \\
(n=59)\end{array}$ & $\begin{array}{c}\text { Total } \\
(n=101)\end{array}$ & $P$ \\
\hline \multicolumn{5}{|l|}{ Primary Outcomes } \\
\hline Endotracheal intubation, no. (\%) & $28(66.7)$ & $26(44.1)$ & $54(53.5)$ & .03 \\
\hline Time to endotracheal intubation $(\mathrm{h})$ & $5.5(1.25-23)$ & $8(2-28)$ & $8(2-24)$ & .97 \\
\hline Duration of ICU stay, $\mathrm{d}$ & $7.5(4.8-18.5)$ & $7(4-14)$ & $7(4-14.5)$ & .80 \\
\hline Duration of hospital stay, $\mathrm{d}$ & $12.5(9-28)$ & $13(5-29)$ & $13(7-28)$ & .53 \\
\hline \multicolumn{5}{|l|}{ Secondary Outcomes } \\
\hline Time to maximum IPAP, $h$ & $2(1-2.3)$ & $2(1-4)$ & $2(1-4)$ & .30 \\
\hline Time to maximum EPAP, $\mathrm{h}$ & $1(1-2)$ & $1(1-2)$ & $1(1-2)$ & .76 \\
\hline Duration of NIV, h & $12(3-24.5)$ & $16(4-36)$ & $14(4-33)$ & .19 \\
\hline Hospital mortality for 92 subjects, no. (\%) & $16(42.1)$ & $14(25.9)$ & $30(32.6)$ & .10 \\
\hline \multicolumn{5}{|l|}{$\begin{array}{l}\text { All values are provided as median (IQR) unless otherwise stated. } \\
\text { NIV = noninvasive ventilation } \\
\text { IPAP = inspiratory positive airway pressure } \\
\text { EPAP = expiratory positive airway pressure }\end{array}$} \\
\hline
\end{tabular}

Table 7. Factors Predicting NIV Failure: Multivariate Logistic Regression Model

\begin{tabular}{lcc}
\hline \hline \multicolumn{1}{c}{ Variable } & $\begin{array}{c}\text { Adjusted Odds Ratio } \\
(95 \% \mathrm{CI})\end{array}$ & $P$ \\
\hline $\begin{array}{l}\text { Change in } \mathrm{pH} \text { at } 1 \text { hour from baseline } \\
\text { Change in } \mathrm{P}_{\mathrm{aO}_{2}} / \mathrm{F}_{\mathrm{IO}_{2}} \text { at } 1 \text { hour from }\end{array}$ & $0.003(0.000-30.33)$ & .21 \\
$\quad$ baseline & $0.993(0.987-0.999)$ & .02 \\
$\Delta \mathrm{f}$ at 1 hour from baseline & $0.985(0.940-1.032)$ & .53 \\
APACHE II score at baseline & $1.169(1.047-1.305)$ & .005 \\
Hypoxemic respiratory failure & $4.571(1.458-14.33)$ & .009 \\
$\Delta$ SOFA score (maximum-baseline) & $1.401(1.085-1.809)$ & .01
\end{tabular}

NIV = noninvasive ventilation

$\mathrm{f}=$ respiratory frequency

APACHE $=$ Acute Physiology and Chronic Health Evaluation

SOFA $=$ Sequential Organ Failure Assessment

Simplified Acute Physiology Score II $\geq 35$, ALI/ARDS or pneumonia as etiology of ARF, $\mathrm{P}_{\mathrm{aO}_{2}} / \mathrm{F}_{\mathrm{IO}_{2}} \leq 146 \mathrm{~mm} \mathrm{Hg}$ after 1 hour of NIV predicted NIV failure. ${ }^{35}$ In another large study involving patients with ALI/ARDS, Simplified Acute Physiology Score II $\geq 35$ and $\mathrm{P}_{\mathrm{aO}_{2}} / \mathrm{F}_{\mathrm{IO}_{2}} \leq 175 \mathrm{~mm} \mathrm{Hg}$ after 1 hour of NIV predicted a higher likelihood of intubation. ${ }^{51}$ In our study a $\mathrm{P}_{\mathrm{aO}_{2}} / \mathrm{F}_{\mathrm{IO}_{2}}$ of $\leq 146 \mathrm{~mm} \mathrm{Hg}$ had a better specificity, as compared to a $\mathrm{P}_{\mathrm{aO}_{2}} / \mathrm{F}_{\mathrm{IO}_{2}} \leq 175 \mathrm{~mm} \mathrm{Hg}$, meaning that failure to achieve $\mathrm{a}_{\mathrm{aO}_{2}} / \mathrm{F}_{\mathrm{IO}_{2}}>146 \mathrm{~mm} \mathrm{Hg}$ at 1 hour is associated with higher risk of NIV failure. However, the $\mathrm{P}_{\mathrm{aO}} / \mathrm{F}_{\mathrm{IO}_{2}}$ at 1 hour did not predict NIV failure in hypercapnic respiratory failure. Another important predictor of NIV failure has been the severity of the underlying illness, as assessed by APACHE II or similar scoring systems, ${ }^{35,36}$ although some studies have failed to demonstrate this observation. ${ }^{21,22,39,62-65}$ In this study the baseline APACHE II scores and the $\triangle$ SOFA score predicted NIV failure. Hence, it is important not only to select patients properly, as unselected patients (eg, ALI/ARDS with shock) have uniformly poor outcomes, ${ }^{50}$ but the duration of NIV trial also requires close observation with monitoring of clinical and blood gas parameters.

\section{Conclusions}

In this observational study of patients receiving NIV in our institution, based on the established protocols, 


\section{A Survey of Noninvasive Ventilation Practices in a Respiratory ICU of North India}

NIV was found to be a useful modality in management of hypercapnic respiratory failure of various etiologies; however, it should be judiciously used in patients with hypoxemic respiratory failure. The disease severity at admission, occurrence of new organ dysfunction, hypoxemic $\mathrm{ARF}$, and delay in improvement in $\mathrm{P}_{\mathrm{aO}_{2}} / \mathrm{F}_{\mathrm{IO}_{2}}$ at 1 hour from baseline were independent predictors of poor outcome with the use of NIV.

\section{REFERENCES}

1. Sullivan CE, Issa FG, Berthon-Jones M, Eves L. Reversal of obstructive sleep apnoea by continuous positive airway pressure applied through the nares. Lancet 1981;1(8225):862-865.

2. Ellis ER, Bye PT, Bruderer JW, Sullivan CE. Treatment of respiratory failure during sleep in patients with neuromuscular disease. Positive-pressure ventilation through a nose mask. Am Rev Respir Dis 1987;135(1):148-152.

3. Brochard L, Mancebo J, Elliott MW. Noninvasive ventilation for acute respiratory failure. Eur Respir J 2002;19(4):712-721.

4. Brochard L, Mancebo J, Wysocki M, Lofaso F, Conti G, Rauss A, et al. Noninvasive ventilation for acute exacerbations of chronic obstructive pulmonary disease. N Engl J Med 1995;333(13):817-822.

5. Plant PK, Owen JL, Elliott MW. Early use of non-invasive ventilation for acute exacerbations of chronic obstructive pulmonary disease on general respiratory wards: a multicentre randomised controlled trial. Lancet 2000;355(9219):1931-1935.

6. Plant PK, Owen JL, Elliott MW. Non-invasive ventilation in acute exacerbations of chronic obstructive pulmonary disease: long term survival and predictors of in-hospital outcome. Thorax 2001;56(9): 708-712.

7. Ram FS, Picot J, Lightowler J, Wedzicha JA. Non-invasive positive pressure ventilation for treatment of respiratory failure due to exacerbations of chronic obstructive pulmonary disease. Cochrane Database Syst Rev 2004(3):CD004104.

8. DerSimonian R, Laird N. Meta-analysis in clinical trials. Control Clin Trials 1986;7(3):177-188

9. Scala R. Noninvasive ventilation in severe acute asthma? Still far from the truth. Respir Care 2010;55(5):630-637.

10. Agarwal R, Aggarwal AN, Gupta D, Jindal SK. Role of noninvasive positive-pressure ventilation in postextubation respiratory failure: a meta-analysis. Respir Care 2007;52(11):1472-1479.

11. Girault C, Bubenheim M, Abroug F, Diehl JL, Elatrous S, Beuret P, et al. Non-invasive ventilation and weaning in chronic hypercapnic respiratory failure patients: a randomized multicenter trial. Am J Respir Crit Care Med 2011;184(6):672-679.

12. Antonelli M, Pennisi MA, Conti G. New advances in the use of noninvasive ventilation for acute hypoxaemic respiratory failure. Eur Respir J 2003;42(Suppl):65S-71S.

13. Keenan SP, Sinuff T, Cook DJ, Hill NS. Does noninvasive positive pressure ventilation improve outcome in acute hypoxemic respiratory failure? A systematic review. Crit Care Med 2004;32(12):2516-2523.

14. Agarwal R, Reddy C, Aggarwal AN, Gupta D. Is there a role for noninvasive ventilation in acute respiratory distress syndrome? A meta-analysis. Respir Med 2006;100(12):2235-2238.

15. Antonelli M, Conti G, Bufi M, Costa MG, Lappa A, Rocco M, et al. Noninvasive ventilation for treatment of acute respiratory failure in patients undergoing solid organ transplantation: a randomized trial. JAMA 2000;283(2):235-241.

16. Auriant I, Jallot A, Hervé P, Cerrina J, Le Roy Ladurie F, Fournier $\mathrm{JL}$, et al. Noninvasive ventilation reduces mortality in acute respiratory failure following lung resection. Am J Respir Crit Care Med 2001;164(7):1231-1235.
17. Hilbert G, Gruson D, Vargas F, Valentino R, Gbikpi-Benissan G, Dupon $\mathrm{M}$, et al. Noninvasive ventilation in immunosuppressed patients with pulmonary infiltrates, fever, and acute respiratory failure. N Engl J Med 2001;344(7):481-487.

18. Agarwal R, Aggarwal AN, Gupta D, Jindal SK. Non-invasive ventilation in acute cardiogenic pulmonary oedema. Postgrad Med J 2005;81(960):637-643.

19. Agarwal R, Aggarwal AN, Gupta D. Is noninvasive pressure support ventilation as effective and safe as continuous positive airway pressure in cardiogenic pulmonary oedema? Singapore Med J 2009;50(6): 595-603.

20. Gray A, Goodacre S, Newby DE, Masson M, Sampson F, Nicholl J. Noninvasive ventilation in acute cardiogenic pulmonary edema. N Engl J Med 2008;359(2):142-151.

21. Agarwal R, Gupta R, Aggarwal AN, Gupta D. Noninvasive positive pressure ventilation in acute respiratory failure due to COPD vs other causes: effectiveness and predictors of failure in a respiratory ICU in North India. Int J Chron Obstruct Pulmon Dis 2008;3(4):737-743.

22. Agarwal R, Handa A, Aggarwal AN, Gupta D, Behera D. Outcomes of noninvasive ventilation in acute hypoxemic respiratory failure in a respiratory intensive care unit in north India. Respir Care 2009; 54(12):1679-1687.

23. Gupta D, Nath A, Agarwal R, Behera D. A prospective randomized controlled trial on the efficacy of noninvasive ventilation in severe acute asthma. Respir Care 2010;55(5):536-543.

24. Singh VK, Khanna P, Rao BK, Sharma SC, Gupta R. Outcome predictors for non-invasive positive pressure ventilation in acute respiratory failure. J Assoc Physicians India 2006;54:361-365.

25. George IA, John G, John P, Peter JV, Christopher S. An evaluation of the role of noninvasive positive pressure ventilation in the management of acute respiratory failure in a developing country. Indian J Med Sci 2007;61(9):495-504.

26. Gold PM. The 2007 GOLD Guidelines: a comprehensive care framework. Respir Care 2009;54(8):1040-1049.

27. Agarwal R, Aggarwal AN, Gupta D, Behera D, Jindal SK. Etiology and outcomes of pulmonary and extrapulmonary acute lung injury/ ARDS in a respiratory ICU in North India. Chest 2006;130(3): 724-729.

28. Martin TJ, Hovis JD, Costantino JP, Bierman MI, Donahoe MP, Rogers RM, et al. A randomized, prospective evaluation of noninvasive ventilation for acute respiratory failure. Am J Respir Crit Care Med 2000;161(3 Pt 1):807-813.

29. BaHammam A, Syed S, Al-Mughairy A. Sleep-related breathing disorders in obese patients presenting with acute respiratory failure. Respir Med 2005;99(6):718-725.

30. Farha S, Ghamra ZW, Hoisington ER, Butler RS, Stoller JK. Use of noninvasive positive-pressure ventilation on the regular hospital ward: experience and correlates of success. Respir Care 2006;51(11): 1237-1243.

31. Ferrer M, Esquinas A, Leon M, Gonzalez G, Alarcon A, Torres A. Noninvasive ventilation in severe hypoxemic respiratory failure: a randomized clinical trial. Am J Respir Crit Care Med 2003;168(12): 1438-1444.

32. Antonelli M, Conti G, Rocco M, Bufi M, De Blasi RA, Vivino G, et al. A comparison of noninvasive positive-pressure ventilation and conventional mechanical ventilation in patients with acute respiratory failure. N Engl J Med 1998;339(7):429-435.

33. Tallman TA, Peacock WF, Emerman CL, Lopatin M, Blicker JZ, Weber $\mathrm{J}$, et al. Noninvasive ventilation outcomes in 2,430 acute decompensated heart failure patients: an ADHERE Registry Analysis. Acad Emerg Med 2008;15(4):355-362.

34. Afessa B, Morales IJ, Scanlon PD, Peters SG. Prognostic factors, clinical course, and hospital outcome of patients with chronic ob- 


\section{A Survey of Noninvasive Ventilation Practices in a Respiratory ICU of North India}

structive pulmonary disease admitted to an intensive care unit for acute respiratory failure. Crit Care Med 2002;30(7):1610-1615.

35. Antonelli M, Conti G, Moro ML, Esquinas A, Gonzalez-Diaz G, Confalonieri M, et al. Predictors of failure of noninvasive positive pressure ventilation in patients with acute hypoxemic respiratory failure: a multi-center study. Intensive Care Med 2001;27(11): 1718-1728.

36. Phua J, Kong K, Lee KH, Shen L, Lim TK. Noninvasive ventilation in hypercapnic acute respiratory failure due to chronic obstructive pulmonary disease vs other conditions: effectiveness and predictors of failure. Intensive Care Med 2005;31(4):533-539.

37. Koschel D, Handzhiev S, Wiedemann B, Hoffken G. Acute effects of NPPV in interstitial lung disease with chronic hypercapnic respiratory failure. Respir Med 2010;104(2):291-295.

38. Caples SM, Gay PC. Noninvasive positive pressure ventilation in the intensive care unit: a concise review. Crit Care Med 2005;33(11): 2651-2658.

39. Meduri GU, Turner RE, Abou-Shala N, Wunderink R, Tolley E. Noninvasive positive pressure ventilation via face mask. First-line intervention in patients with acute hypercapnic and hypoxemic respiratory failure. Chest 1996;109(1):179-193.

40. Wysocki M, Tric L, Wolff MA, Millet H, Herman B. Noninvasive pressure support ventilation in patients with acute respiratory failure. A randomized comparison with conventional therapy. Chest 1995; 107(3):761-768.

41. Bott J, Carroll MP, Conway JH, Keilty SE, Ward EM, Brown AM, et al. Randomised controlled trial of nasal ventilation in acute ventilatory failure due to chronic obstructive airways disease. Lancet 1993;341(8860):1555-1557.

42. Kramer N, Meyer TJ, Meharg J, Cece RD, Hill NS. Randomized, prospective trial of noninvasive positive pressure ventilation in acute respiratory failure. Am J Respir Crit Care Med 1995;151(6): 1799-1806.

43. Celikel T, Sungur M, Ceyhan B, Karakurt S. Comparison of noninvasive positive pressure ventilation with standard medical therapy in hypercapnic acute respiratory failure. Chest 1998;114(6):1636-1642.

44. L'Her E, Deye N, Lellouche F, Taille S, Demoule A, Fraticelli A, et al. Physiologic effects of noninvasive ventilation during acute lung injury. Am J Respir Crit Care Med 2005;172(9):1112-1118.

45. Agarwal R, Aggarwal AN, Gupta D. Role of noninvasive ventilation in acute lung injury/acute respiratory distress syndrome: a proportion meta-analysis. Respir Care 2010;55(12):1653-1660.

46. Nava S, Ceriana P. Causes of failure of noninvasive mechanical ventilation. Respir Care 2004;49(3):295-303.

47. Domenighetti G, Gayer R, Gentilini R. Noninvasive pressure support ventilation in non-COPD patients with acute cardiogenic pulmonary edema and severe community-acquired pneumonia: acute effects and outcome. Intensive Care Med 2002;28(9):1226-1232.

48. Demoule A, Girou E, Richard JC, Taille S, Brochard L. Increased use of noninvasive ventilation in French intensive care units. Intensive Care Med 2006;32(11):1747-1755.

49. Hilbert G, Gruson D, Vargas F, Valentino R, Chene G, Boiron JM, et al. Noninvasive continuous positive airway pressure in neutropenic patients with acute respiratory failure requiring intensive care unit admission. Crit Care Med 2000;28(9):3185-3190.
50. Rana S, Jenad H, Gay PC, Buck CF, Hubmayr RD, Gajic O. Failure of non-invasive ventilation in patients with acute lung injury: observational cohort study. Crit Care 2006;10(3):R79.

51. Antonelli M, Conti G, Esquinas A, Montini L, Maggiore SM, Bello $\mathrm{G}$, et al. A multiple-center survey on the use in clinical practice of noninvasive ventilation as a first-line intervention for acute respiratory distress syndrome. Crit Care Med 2007;35(1):18-25.

52. Soroksky A, Stav D, Shpirer I. A pilot prospective, randomized, placebo-controlled trial of bilevel positive airway pressure in acute asthmatic attack. Chest 2003;123(4):1018-1025.

53. Lisboa C, Diaz O, Fadic R. [Noninvasive mechanical ventilation in patients with neuromuscular diseases and in patients with chest restriction]. Arch Bronconeumol 2003;39(7):314-320. Article in Spanish.

54. Rabinstein A, Wijdicks EF. BiPAP in acute respiratory failure due to myasthenic crisis may prevent intubation. Neurology 2002;59(10): 1647-1649.

55. Agarwal R, Reddy C, Gupta D. Noninvasive ventilation in acute neuromuscular respiratory failure due to myasthenic crisis: case report and review of literature. Emerg Med J 2006;23(1):e6

56. Seneviratne J, Mandrekar J, Wijdicks EF, Rabinstein AA. Noninvasive ventilation in myasthenic crisis. Arch Neurol 2008;65(1):54-58.

57. Demoule A, Girou E, Richard JC, Taille S, Brochard L. Benefits and risks of success or failure of noninvasive ventilation. Intensive Care Med 2006;32(11):1756-1765.

58. Festic E, Gajic O, Limper AH, Aksamit TR. Acute respiratory failure due to pneumocystis pneumonia in patients without human immunodeficiency virus infection: outcome and associated features. Chest 2005;128(2):573-579.

59. Wood KA, Lewis L, Von Harz B, Kollef MH. The use of noninvasive positive pressure ventilation in the emergency department: results of a randomized clinical trial. Chest 1998;113(5):1339-1346.

60. Girault C, Daudenthun I, Chevron V, Tamion F, Leroy J, Bonmarchand G. Noninvasive ventilation as a systematic extubation and weaning technique in acute-on-chronic respiratory failure: a prospective, randomized controlled study. Am J Respir Crit Care Med 1999; 160(1):86-92.

61. Soo Hoo GW, Santiago S, Williams AJ. Nasal mechanical ventilation for hypercapnic respiratory failure in chronic obstructive pulmonary disease: determinants of success and failure. Crit Care Med 1994;22(8):1253-1261.

62. Anton A, Guell R, Gomez J, Serrano J, Castellano A, Carrasco JL, et al. Predicting the result of noninvasive ventilation in severe acute exacerbations of patients with chronic airflow limitation. Chest 2000; 117(3):828-833.

63. Lightowler JV, Elliott MW. Predicting the outcome from NIV for acute exacerbations of COPD. Thorax 2000;55(10):815-816.

64. Benhamou D, Girault C, Faure C, Portier F, Muir JF. Nasal mask ventilation in acute respiratory failure. Experience in elderly patients. Chest 1992;102(3):912-917.

65. Moretti M, Cilione C, Tampieri A, Fracchia C, Marchioni A, Nava $\mathrm{S}$. Incidence and causes of non-invasive mechanical ventilation failure after initial success. Thorax 2000;55(10):819-825. 